\title{
Simultaneous Determination of Dimethadione and Trimethadione by Infrared-Spectrometry: Application for Mean Intracellular pH Measurement
}

\author{
By J. Zweens') and Henny Frankena \\ Department of Physiology, University of Groningen, The Netherlands
}

(Received March 12/May 14, 1984)

Summary: A simple infrared-spectrometric method for the simultaneous determination of dimethadione and trimethadione in plasma is described. The method is based on the absorption band of the carbonyl group for trimethadione at the wavenumber of $1740 \mathrm{~cm}^{-1}$ and for dimethadione at the wavenumber of $1770 \mathrm{~cm}^{-1}$. The accuracy and precison of the method are excellent; at a dimethadione and trimethadione concentration of 0.5 $\mathrm{mmol} \cdot \mathrm{l}^{-1}$ the coefficient of variation for the determination of both compounds is $<1 \%$, which is better than that for the ultraviolet spectrometric or gas-liquid chromatographic methods. The method can be used for the determination of the ratio trimethadione/dimethadione in the clinical setting as a sensitive check of the patient's adherence to therapy. It can also be used for the determination of dimethadione as an indicator for the mean body intracellular $\mathrm{pH}$.

\section{Simultane Bestimmung von Di- und Trimethadion durch Infrarot-Spektrometrie: Anwendung zur Bestimmung des mittleren intrazellulären $\mathrm{pH}$}

Zusammenfassung: Eine einfache Methode zur simultanen infrarotspektrometrischen Bestimmung von Diund Trimethadion im Plasma wird beschrieben. Die Methode beruht auf der Absorptionsbande der Carbonylgruppe bei der Wellenzahl $1740 \mathrm{~cm}^{-1}$ für Trimethadion und $1770 \mathrm{~cm}^{-1}$ für Dimethadion. Richtigkeit und Präzision der Methode sind hervorragend; bei einer Di- bzw. Trimethadionkonzentration von $0,5 \mathrm{mmol} \cdot \mathrm{I}^{-1}$ beträgt der Variationskoeffizient $<1 \%$ und ist besser als der ultraviolettspektrometrischer oder gaschromatographischer Methoden. Die Methode kann zur Bestimmung des Quotienten Trimethadion/Dimethadion als empfindliche Kenñgröße für die Zuverlässigkeit des Patienten in der Medikamenteneinnahme während klinischer Therapie eingesetẑt werden. Die Bestimmung von Dimethadion kann als Maß für den mittleren intrazellulären pH-Wert im Körpẹ benutzt werden.

\section{Introduction}

Trimethadione (3,5,5-trimethyl-oxazolidinedione) and its major metabolite dimethadione (5,5-dimethyl-oxazolidinedione) are anticonvulsive agents, formerly used in the treatment of epilepsy. Trimethadione is now only used in the treatment of absence seizures. Dimethadione, however, remains of

\footnotetext{
1) Present address: Medical Department Eli Lilly Nederland, Stationsplein 97, NL-3511 ED Utrecht.
}

interest in physiology and experimental medicine as an indicator in the measurement of the mean body intracellular $\mathrm{pH}\left(\mathrm{pH}_{\mathrm{i}}\right)$ according to Waddell \& Butler (1).

The concentration of dimethadione in tissues and plasma is measured by ultraviolet (UV) spectrometry (1), and by the use of ${ }^{14} \mathrm{C}$-labelled dimethadione (2), while gas-liquid chromatography has also been used for this purpose (3). Gas-liquid chromatography allows the simultaneous determination of dimethadione and trimethadione, but suffers from an in- 
complete recovery of dimethadione. The UV-spectrometric method consists of two consecutive extraction steps, which renders the method quite laborious and time-consuming and decreases the accuracy. Determination of dimethadione by the ${ }^{14} \mathrm{C}$-isotope method is expensive and requires the facilities of liquid scintillation counting.

In this paper, we describe an infrared (IR)-spectrometric method which can be used in the determination of $\mathrm{pH}_{\mathrm{i}}$ and for the simultaneous measurement of dimethadione and trimethadione in plasma. The method is compared with the UV-spectrometric method with regard to sensitivity, accuracy and precision.

\section{Methods and Experiments}

IR-spectrometric deternination of dimethadione and trimethadione

IR-spectrometric determination of dimethadione and trimethadione is based on the strong carbonyl absorption band between 1700 and $1800 \mathrm{~cm}^{-1}$. Dimethadione and trimethadione can be measured after extraction from plasma into chloroform, the spectrum of which has low absorption in the carbonyl absorption region. For this purpose the following method was adopted.

Deproteinize by adding $0.1 \mathrm{ml} \mathrm{HClO}_{4} 12.5 \mathrm{~mol} \cdot \mathrm{I}^{-1}$ to $2.5 \mathrm{ml}$ plasma, mix thoroughly and allow to stand for $5 \mathrm{~min}$. Centrifuge for $10 \mathrm{~min}$ at $2000 \mathrm{~g}$. Transfer $2 \mathrm{ml}$ of the clear supernatant to a test tube containing $10 \mathrm{mmol}$ solid $\mathrm{Na}_{2} \mathrm{SO}_{4}$ and $6 \mathrm{mmol}$ solid $\mathrm{MgSO}_{4}$. and mix for $1 \mathrm{~min}$ on a vortex mixer. Add $1.5 \mathrm{ml}$ chloroform and mix for $1 \mathrm{~min}$ on the vortex mixer. Centrifuge for $10 \mathrm{~min}$ at $2000 \mathrm{~g}$ to separate the phases and measure the absorbance of the chloroform phase against a similarly treated plasma blank at the wavenumber of maximum absorbance (dimethadione, $\lambda^{-1}=$ $1770 \mathrm{~cm}^{-1}$; trimethadione, $\left.\lambda^{-1}=1740 \mathrm{~cm}^{-1}\right)$. Convert the measured absorbances into concentrations with the aid of a calibration line made by mixing different volumes of a stock solution with plasma (homologous or heterologous), the stock solution being plasma containing dimethadione $100 \mathrm{mmol} \cdot \mathrm{I}^{-1}$ and/or trimethadione $50 \mathrm{mmol} \cdot \mathrm{j}^{-1}$. At the wavenumbers used, dimethadione obeys Lambert-Beer's law at least from 0.25 to $5 \mathrm{mmol} \cdot \mathrm{I}^{-1}$ with a molar lineic absorbance of $170 \mathrm{~m}^{2} \cdot \mathrm{mol}^{-1}$, and trimethadione at least from 0.1 to $2 \mathrm{mmol}^{-1}$ with a molar lineic absorbance of 370 $\mathrm{m}^{2} \cdot \mathrm{mol}^{-1}$.

\section{UV-spectrometric determination of dimethadione}

The method of Waddell \& Butler (1) was used, with adaptations for the use of $0.25 \mathrm{ml}$ samples instead of $1 \mathrm{ml}$ samples. The original method, in which the absorbances (A) are measured at $\lambda=$ 215 and $220 \mathrm{~nm}$, was modified in two respects. First, any ether present in the borate buffer after extraction of dimethadione from the ether phase was removed by passing air over the test-tubes. This improves the stability of the absorbance reading and thereby the precision of the method. Second, the absorbance was read at $\lambda$ $=208 \mathrm{~nm}$ (maximum absorbance) and $\lambda=240 \mathrm{~nm}$ (minimum absorbance). The difference between the molar lineic absorbances at these wavelengths is $160 \mathrm{~m}^{2} \cdot \mathrm{mol}^{-1}$ as against $73 \mathrm{~m}^{2} \cdot \mathrm{mol}^{-1}$ at $\lambda=215$ and $220 \mathrm{~nm}$, the wavelengths originally used by Waddell \& Butler.

\section{Experiments in vitro}

To determine the effect of $\mathrm{Na}_{2} \mathrm{SO}_{4}$ and $\mathrm{MgSO}_{4}$ on the partition of dimcthadione between water and chloroform during chloroform extraction of the plasma, $\mathrm{Na}_{2} \mathrm{SO}_{4}$ and $\mathrm{MgSO}_{4}$ were added either separately or together to deproteinized plasma containing dimethadione $1 \mathrm{mmol} \cdot 1^{-1}$. The absorption of the chloroform phase after extraction was measured against a similarly treated plasma blank.

To determine the recovery and precision of the IR-spectrometric methods, dimethadione and trimethadione were added separately to plasma in different concentrations and replicate determinations were performed on these samples.

To determine the recovery and precision of the original UV-spectrometric method $\left(A_{215}-A_{2211}\right)$ and the modified method $\left(A_{201}-A_{2411}\right)$ for dimethadione, dimethadione was added to plasma to a concentration of 0.3 and $0.5 \mathrm{mmol} \cdot \mathrm{I}^{-1}$ and replicate determinations were performed on these samples both with and without removal of ether from the borate phase.

To compare the IR-spectrometric method for dimethadione with the original and the modified UV-spectrometric method with respect to accuracy and precision, dimethadione was added to different plasma samples to a concentration of $0.5 \mathrm{mmol} \cdot \mathrm{I}^{-1}$ and the dimethadione concentration determined with the three methods.

To determine the recovery and precision of the IR-spectrometric method for measuring different mixtures of dimethadione and trimethadione in plasma, dimethadione and trimethadione were added to plasma in different ratios and their concentrations determined by two-component analysis using the molar lineic absorbances for dimethadione and trimethadione at $\lambda^{-1}=1770 \mathrm{~cm}^{-1}$ and $1740 \mathrm{~cm}^{-1}$, which had been determined previously by onecomponent analysis.

\section{Experiments in vivo}

The mean body intracellular $\mathrm{pH}\left(\mathrm{pH}_{\mathrm{i}}\right)$ was calculated in 3 male mongrel dogs with permanent catheters in the aorta and the pulmonary artery (4). The dog, lying quietly in a basket, was given dimethadione $0.15 \mathrm{mmol} \cdot \mathrm{kg}^{-1}$ body mass, dissolved in $\mathrm{D}_{2} \mathrm{O}$, as an indicator for the total body water volume (5), which also contained hexacyanoferrate(II) as indicator for the extracellular water volume (6). The administered amounts of $\mathrm{D}_{2} \mathrm{O}$ and hexacyanoferrate(II) were $1 \mathrm{ml} \cdot \mathrm{kg}^{-1}$ and $0.1 \mathrm{mmol} \cdot \mathrm{kg}^{-1}$, respectively. The indicator was injected through the catheter in the pulmonary artery in about $20 \mathrm{~s}$. Blood samples were taken at $2,5,10,20,30$, 45,60 and $90 \mathrm{~min}, 2,3,4,5,6$ and $7 \mathrm{~h}$, and 1,2 and $3 \mathrm{~d}$ after the injection, zero time being chosen halfway between the start and the end of the injection.

\section{Determination of mean whole body intracellular $\mathrm{pH}$}

The dimethadione method according to Waddell \& Butler (1) is based on the fact that dimethadione is a weak acid which in unionized form easily passes from the extracellular to the intracellular compartment and vice versa. Consequently, the concentration of the unionized form is equal in the two compartments. The concentration of the ionized form, on the other hand, depends on the $\mathrm{pH}$ prevailing in each of the two compartments. For the intracellular compartment:

$$
\mathrm{pH}_{\mathrm{i}}=\mathrm{pK}^{\prime}+\log \frac{\mathrm{c}_{\mathrm{DMO}}^{i}}{\mathrm{c}_{\mathrm{DMO}}^{i}}
$$

where $\mathrm{pH}_{\mathrm{j}}$ is the intracellular $\mathrm{pH}, \mathrm{pK}^{\prime}$ is the apparent ionization constant of dimethadione, and $\mathrm{c}_{\mathrm{DMO}}^{\mathrm{i}}$ - and $\mathrm{c}_{\mathrm{DMO}}^{\mathrm{i}}$ are the intracellular concentrations of ionized and unionized dimethadione, respectively. For the extracellular compartment an analogous relationship holds, from which the following equation for the extracellular concentration of unionized dimethadione ( $\left.c_{\mathrm{DMO}}^{\mathrm{e}} \hat{\prime}^{\prime}\right)$ can be derived:

$$
c_{D M O}^{c}=\frac{c_{D M O}^{c}+c_{D M O-}^{c}}{1+10^{\mathrm{pH}_{\mathrm{c}}-\mathrm{pK}^{\prime}}}
$$

where $c_{D M O}^{c}$ - stands for the extracellular concentration of ionized dimethadione, and $\mathrm{pH}_{\mathrm{e}}$ for the extraceliular $\mathrm{pH}$. By determining 
plasma $\mathrm{pH}$ and the total dimethadione concentration in plasma water, and correcting for Donnan equilibria, ( $\left.c_{D M O}^{c}+c_{D M O}^{c}\right)$ and $\mathrm{pH}_{\mathrm{e}}$ are found. $\mathrm{pK}^{\prime}$ can be derived from an equation given by Albers et al. (2):

$$
\mathrm{pK}^{\prime}=6.464-0.00874 \mathrm{~T}_{\mathrm{b}}
$$

where $T_{b}$ is the body temperature in ${ }^{\circ} \mathrm{C}$. Since $c_{D M O}^{i}=c_{D M O}^{c}$, equation 2 also gives the intracellular concentration of unionized DMO. The intracellular concentration of ionized dimethadione follows from equation 4 ,

$$
c_{D M O-}^{i}=\frac{m_{1}-V_{c}\left(C_{D M O}^{c}+c_{D M O}^{c}\right)}{V_{1}-V_{c}}-c_{D M O}^{i}
$$

where $m_{t}$ is the total amount of dimethadione in the body and $V_{c}$ and $V_{1}$ are the extracellular and total body water volumes, respectively. Once $c_{D M O}^{i}$ and $c_{D M O}^{i}$ - have been determined, $\mathrm{pH}_{\mathrm{i}}$ follows from equation 1 . The loss of dimethadione from the body was corrected for with the aid of the total body clearance as derived from the plasma disappearance curve, an example of which is given in figure 1 .

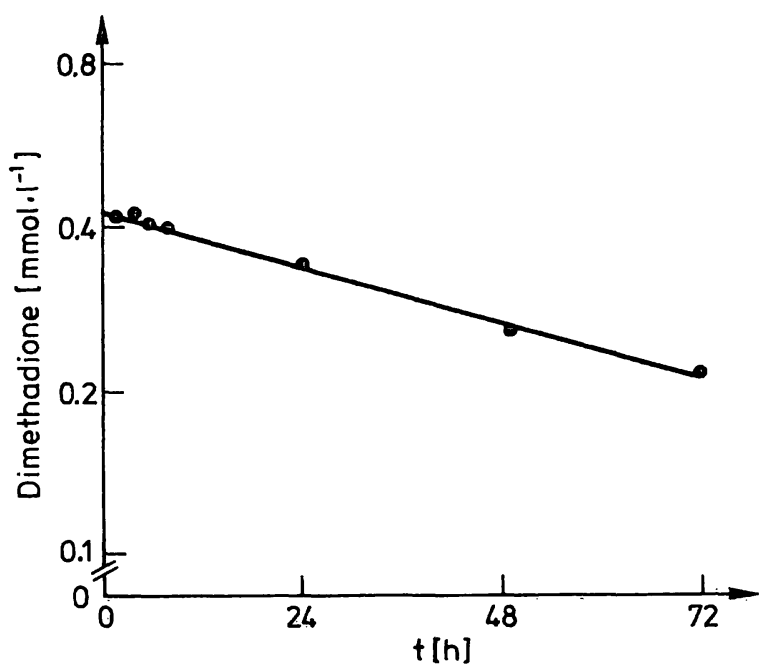

Fig. 1. Disappearance curve of dimethadione from the plasma of a dog after i.v. injection of $0.15 \mathrm{mmol} \cdot \mathrm{kg}^{-1}$ at time 0 . Note the logarithmic scale of the ordinate. The straight line signifies the mono-exponential loss of dimethadione from the body.

\section{Results}

Saturation of the deproteinized plasma with either $\mathrm{Na}_{2} \mathrm{SO}_{4}$ or $\mathrm{MgSO}_{4}$ before chloroform extraction shifts the partition coefficient for dimethadione in favour of chloroform, but the presènce of both salts in excess results in a larger change in partition coefficient and increases the efficacy of the extraction more than threefold.

Table 1 shows data on the accuracy and precision of the separate determination of dimethadione and trimethadione by IR-spectrometry. The recoveries of both added dimethadione and added trimethadione are excellent and the coefficient of variation of the method, measured over the whole concentration range, is $\leqslant 1 \%$.
Data on the accuracy and precision of the UV-spectrometric determinations of dimethadione in plasma are given in table 2. Measuring the absorbance at the wavelength of maximum and minimum absorbance instead of using two wavelengths on the ascending limb of the absorbance curve increases the precision of the method. Removal of ether from the borate buffer in which the absorbances are measured in-

Tab. 1. Recovery and precision of the IR-spectromctric determination of dimethadione $\left(\lambda^{-1}=177() \mathrm{cm}^{-1}\right)$ and trimethadione $\left(\lambda^{-1}=1740 \mathrm{~cm}^{-1}\right)$ in plasma.

\begin{tabular}{lll}
\hline $\begin{array}{l}\text { Dimethadione added } \\
\left(\mathrm{mmol} \cdot \mathrm{I}^{-1}\right)\end{array}$ & $\begin{array}{l}\text { Dimethadione recovered } \\
\left(\mathrm{mmol} \cdot \mathrm{I}^{-1}\right)\end{array}$ & $\begin{array}{l}\mathrm{CV} \\
(\%)\end{array}$ \\
\hline 0.256 & 0.252 & 1.1 \\
0.500 & 0.495 & 1.0 \\
0.750 & 0.747 & 0.8 \\
1.000 & 1.004 & 0.6 \\
2.000 & 1.995 & 0.5 \\
\hline Trimethadione added & Trimethadione recovered & $\mathrm{CV}$ \\
$\left(\mathrm{mmol} \cdot \mathrm{1}^{-1}\right)$ & $\left(\mathrm{mmol} \cdot \mathrm{1}^{-1}\right)$ & $(\%)$ \\
\hline 0.125 & 0.124 & 1.6 \\
0.250 & 0.247 & 0.8 \\
0.500 & 0.503 & 0.6 \\
0.750 & 0.752 & 0.5 \\
1.000 & 0.996 & 0.5 \\
\hline
\end{tabular}

$n=10$ at each concentration; $C V=$ coefficient of variation.

Tab. 2. Recovery and precision of the UV-spectrometric determination of dimethadione in plasma.

\begin{tabular}{lll}
\hline $\begin{array}{l}\text { Measurement at } \lambda=215 \text { and } 220 \mathrm{~nm} \\
\begin{array}{l}\text { Dimethadione } \\
\text { added } \\
\left(\mathrm{mmol} \cdot 1^{-1}\right)\end{array}\end{array}$ & $\begin{array}{l}\text { Dimethadione } \\
\text { recovered } \\
\left(\mathrm{mmol} \cdot \mathrm{I}^{-1}\right)\end{array}$ & $\mathrm{CV}$ \\
\hline 0.300 & 0.294 & 3.2 \\
0.300 & 0.303 & 2.6 ether removed \\
0.500 & 0.507 & 3.0 \\
0.500 & 0.502 & 2.6 ether removed \\
\hline
\end{tabular}

Measurement at $\lambda=208$ and $240 \mathrm{~nm}$

Dimethadione Dimethadione CV

added recovered

$\left(\mathrm{mmol} \cdot \mathrm{1}^{-1}\right) \quad\left(\mathrm{mmol} \cdot \mathrm{1}^{-1}\right)$

\begin{tabular}{lll}
\hline 0.300 & 0.304 & 2.2 \\
0.300 & 0.297 & 2.0 ether removed \\
0.500 & 0.497 & 2.0 \\
0.500 & 0.495 & 1.75 ether removed
\end{tabular}

$n=10$ in each serics; $C V=$ coefficient of variation. 
creases the stability of the readings and thereby further improves the precision of the method. From table 3 it is obvious that the IR-spectrometric method by far excels both UV-spectrometric methods in precision.

Table 4 shows that different mixtures of dimethadione and trimethadione in plasma can be determined with satisfactory accuracy and precision by two-component analysis when the absorbances are measured at $\lambda^{-1}=1770 \mathrm{~cm}^{-1}$ and $1740 \mathrm{~cm}^{-1}$. Table 5 shows $\mathrm{pH}_{\mathrm{i}}$ calculated at 2.4 and $6 \mathrm{~h}$ after the injection of dimethadione in 3 non-anaesthetized dogs.

Tab. 3. Accuracy and precision of the IR-spectrometric determination of dimethadione in comparison with the UV-spectrometric methods.

\begin{tabular}{lllll}
\hline Method & $\therefore$ & $\begin{array}{l}\text { Dimetha- } \\
\text { dionc } \\
\left(\mathrm{mmol} \cdot 1^{-1}\right)\end{array}$ & $\begin{array}{l}\text { Dimetha- } \\
\text { dione } \\
\left(\mathrm{mmol} \cdot \mathrm{1}^{-1}\right)\end{array}$ & $\mathrm{CV}$ \\
\hline IR-spectrometry & 0.500 & 0.502 & 0.8 \\
UV-spectrometry $\left(\mathrm{A}_{215}-\mathrm{A}_{220)}\right)$ & 0.50() & 0.511 & 2.9 \\
UV-spectrometry $\left(\mathrm{A}_{2106}-\mathrm{A}_{240}\right)$ & 0.500 & 0.506 & 1.8 \\
\hline
\end{tabular}

$\mathrm{n}=10$ in each scries; $\mathrm{CV}=$ coefficient of variation.

Tab. 4. Recovery and precision of the determination of different mixtures of dimethadione and trimethadione in plasma by IR-spectrometry.

\begin{tabular}{llll}
\hline $\begin{array}{l}\text { Dimetha- } \\
\text { dionc } \\
\text { added } \\
\left(\mathrm{mmol} \cdot \mathrm{I}^{-1}\right)\end{array}$ & $\begin{array}{l}\text { Dimetha- } \\
\text { dione } \\
\text { recovered } \\
\left(\mathrm{mmol} \cdot \mathrm{I}^{-1}\right)\end{array}$ & $\begin{array}{l}\text { Trimetha- } \\
\text { dione } \\
\text { added } \\
\left(\mathrm{mmol} \cdot \mathrm{I}^{-1}\right)\end{array}$ & $\begin{array}{l}\text { Trimetha- } \\
\text { dione } \\
\text { recovered } \\
\left(\mathrm{mmol} \cdot \mathrm{I}^{-1}\right)\end{array}$ \\
\hline 0.99 & $0.98 \pm 0.02$ & 1.98 & $1.90 \pm 0.02$ \\
1.98 & $1.97 \pm 0.04$ & 1.49 & $1.52 \pm 0.03$ \\
2.97 & $2.94 \pm 0.03$ & 0.99 & $0.97 \pm 0.04$ \\
3.96 & $3.91 \pm 0.03$ & 0.49 & $0.51 \pm 0.04$ \\
\hline
\end{tabular}

$n=4$ in each series.

Tab. 5. Mean body intracellular $\mathrm{pH}\left(\mathrm{pH}_{\mathrm{i}}\right)$ and plasma $\mathrm{pH}\left(\mathrm{pH}_{\mathrm{p}}\right)$ at 2, 4 and $6 \mathrm{~h}$ after injection of dimethadione.

\begin{tabular}{rlll}
\hline & $2 \mathrm{~h}$ & $4 \mathrm{~h}$ & $6 \mathrm{~h}$ \\
\hline Dog 1 $\mathrm{pH}_{\mathrm{i}}$ & 6.95 & 6.95 & 6.97 \\
$\mathrm{pH}_{\mathrm{p}}$ & 7.41 & 7.41 & 7.43 \\
$\operatorname{Dog} 2 \mathrm{pH}_{\mathrm{i}}$ & 6.95 & 6.93 & 6.88 \\
$\mathrm{pH}_{\mathrm{p}}$ & 7.45 & 7.43 & 7.39 \\
$\operatorname{Dog} 3 \mathrm{pH}_{\mathrm{i}}$ & 6.94 & 6.95 & 6.94 \\
$\mathrm{pH}_{\mathrm{p}}$ & 7.42 & 7.42 & 7.41 \\
\hline
\end{tabular}

\section{Discussion}

As shown in table 3, the IR-spectrometric determination of dimethadione is more precise than determinations by the original and modified UV-spectrophotometric methods. Removal of ether from the borate buffer and reading the absorbance at the wavelength of maximum and minimum absorbance improves the coefficient of variation from about 3\% to about $2 \%$ (tab. 2), which is still considerably above that of the IR-spectrometric method (tab. 1). This difference in precision probably originates from the fact that the UV-method is a two-step extraction procedure, whereas the IR-method involves only a single extraction step.

The amount of sulphate salts used to influence the partition coefficient of dimethadione in a chloroform-water system is not of critical importance, providing both salts are present in excess. Addition of less salt than is needed to saturate the solution results in a decreased extraction into chloroform. Extraction of dimethadione from plasma into chloroform is sensitive to the $\mathrm{pH}$ of the water phase, owing to the influence of $\mathrm{pH}$ on the unionized dimethadione. $\mathrm{A}$ pH below 3 gives maximum extraction, and acid deproteinization of the plasma serves this purpose well. The extraction of trimethadione into chloroform is virtually uninfluenced by the presence of sulphate salts.

Trimethadione has lost much of its clinical importance and is employed only in the treatment of absence seizures in patients who are not adequately controlled by or do not tolerate other drugs. Trimethadione is largely demethylated in the liver to the active metabolite dimethadione, which is excreted unchanged in the urine. The biological half-life of trimethadione $(8 \mathrm{~h})$ is about twenty times shorter than that of dimethadione $(6-13 \mathrm{~d})$ and a ratio trimethadione/dimethadione substantially higher than $1 / 2$ usually implies that the patient has not been taking medication regularly (7). Our method, which allows simultaneo'ds measurement of trimethadione and dimethadione, enables an easy and sufficiently sensitive check of the patient's adherence to the therapy.

Dimethadione can be used as an indicator for $\mathrm{pH}_{\mathrm{i}}$ when plasma $\mathrm{pH}$, the total body water volume and the extracellular water volume are known. Figure 1 gives a plasma disappearance curve of dimethadione in a $40 \mathrm{~kg}$ dog following the administration of 0.15 mmol dimethadione per $\mathrm{kg}$ body mass and shows that the biological half-life of dimethadione can be determined in the individual animial. Since the distribution volume and the biological half-life of dime- 
thadione are similar in man and dog, the same will hold for man. The distribution volume of dimethadione is about $40 \%$ of the total body mass and administration of $0.10 \mathrm{mmol}$ dimethadione per $\mathrm{kg}$ body mass will thus result in a plasma concentration of about $0.25 \mathrm{mmol} \cdot 1^{-1}$. This plasma concentration can be measured accurately and is far below the toxic level. The concentration after $48 \mathrm{~h}$ may, however, be too low to accurately measure the biological half-life of dimethadione, but with the use of an average total body clearance based on published data (2), the possible error over a $6 \mathrm{~h}$ measuring period will be $2 \%$ or less.

In their discussion of the errors involved in the determination of $\mathrm{pH}_{\mathrm{i}}$, Albers et al. $(2,8)$ stress the importance of the accuracy of the determination of the extracellular water volume and the total amount of dimethadione in the body, and to a lesser degree that of the determination of the total body water volume. In the described method $V_{e}$ and $V_{1}$ were only determined once on the basis of the distribution of hexacyanoferrate II and $\mathrm{D}_{2} \mathrm{O}$, respectively, and the loss of dimethadione from the body was calculated from the individual disappearance curve of dimethadione. If, during the observation period, the distribution of dimethadione had changed as the result of an intercompartmental water shift, or if the correction for dimethadione loss from the body had been seriously in error, a shift in $\mathrm{pH}_{\mathrm{i}}$ relative to $\mathrm{pH}_{\mathrm{p}}$ would have been observed. Table 5, however, shows that the difference between $\mathrm{pH}_{\mathrm{p}}$ and $\mathrm{pH}_{\mathrm{i}}$ was remarkably constant over the six-hour observation periods in all three dogs. This indicates that, at least under the conditions of our experiment, the chosen procedure is justified.

The described IR-spectrometric method provides a means for the simultaneous measurement of dimethadione and trimethadione in the therapeutic monitoring of patients. It is more sensitive and precise, and less laborious, than the original or modified UVspectrometric method and offers an alternative to the use of ${ }^{14} \mathrm{C}$-labelled dimethadione for the experimental and clinical measurement of $\mathrm{pH}_{\mathrm{i}}$.

\section{References}

1. Waddell, W. J. \& Butler, T. C. (1959) J. Clin. Invest. 38, 720-729.

2. Albers, C., Saborowski, F., Usinger, W. \& Scholand, Ch. (1975) Respir. Physiol. 23, 49-57.

3. Booker, H. E. \& Darcey, B. (1971) Clin. Chem. 7, 607-609.

4. Zweens, J. \& Schiphof, P. (1976) Pflügers Arch. 362, 201202.

5. Zweens, J., Frankena, H., Reicher, A. \& Zijlstra, W. G. (1980) Pflügers Arch. 385, 71-77.

6. Zweens, J., Frankena, H. \& Zijlstra, W. G. (1978) Pflügers Arch. 376, 131-138.

7. Woodburry, D. M., Penry, J. K. \& Schmidt, R. P. (1971) Antiepileptic drugs, Raven Press, New York.

8. Albers, C., Ludwig, O., Usinger, W. \& Spaich, P. (1971) Respir. Physiol. 11, 197-210.

Prof. Dr. W. G. Zijlstra

Department of Physiology

University of Groningen

Bloemsingel 10

NL-9712 KZ Groningen 
$+$ 